\title{
Unsteady Approximate Model of Grouting in Fractured Channels Based on Bingham Fluid
}

\author{
Bo Ren $(\mathbb{D}$, Lianguo Wang $(\mathbb{D}$, Hao Fan, Ke Ding $(\mathbb{D}$, Kai Wang, and Chongyang Jiang \\ State Key Laboratory for Geomechanics and Deep Underground Engineering, China University of Mining and Technology, Xuzhou, \\ Jiangsu 221116, China \\ Correspondence should be addressed to Lianguo Wang; cumt_lgwang@163.com
}

Received 1 December 2020; Revised 17 January 2021; Accepted 16 March 2021; Published 28 March 2021

Academic Editor: Jia Liu

Copyright (C) 2021 Bo Ren et al. This is an open access article distributed under the Creative Commons Attribution License, which permits unrestricted use, distribution, and reproduction in any medium, provided the original work is properly cited.

\begin{abstract}
It is of great significance for the improvement of grouting technology and engineering practice to master the flow law of grout between parallel plates. However, the traditional calculation model ignores the influence of the inertia term and only considers the stable flow of slurry, so there is a big error in some cases. It is difficult to solve the motion equation of a Bingham fluid considering the inertial force term directly. Combined with the relationship between the steady-state flow equation of a Bingham fluid and a Newtonian fluid, the approximate unsteady-state flow equation of a Bingham fluid suitable for describing slurry flow is constructed. In addition, according to the unsteady flow equation, the relationship between the time and distance of slurry flow in parallel plate fractures can be obtained, and the simplified conditions of the Bingham fluid unsteady flow model are given. Finally, the accuracy of the flow equations and the simplified conditions are verified by experiments and numerical calculations.
\end{abstract}

\section{Introduction}

Grouting technology is widely used in many fields such as mining, tunneling, landfilling of municipal solid waste, storage of nuclear waste, and development and utilization of underground space. In coal mining, a soft rock roadway is often strengthened by grouting to prevent roadway damage or large deformation during roadway excavation [1-4]. Bad geological bodies such as lava and faults will have many adverse effects on the construction during the tunneling process. Grouting into the faults can increase the integrity of the rock mass and ensure safe and efficient construction [5-7]. Landfill of municipal solid waste $[8,9]$ requires grouting and antiseepage treatment in the buried pits that have been dug in advance to avoid water and soil pollution caused by toxic gas and liquid penetration. In the same way, nuclear waste storage $[10,11]$ also needs to consider the environmental impact of radioactive materials and consider strengthening the surrounding areas of the rock to avoid irreparable damage. In the long run, the scope of human activities is becoming wider and wider, and the use of underground space is gradually being put on the agenda. The use of underground space will certainly use grouting technology. So far, the method of grouting is more environmentally friendly, economical, and effective than other methods.

However, in a grouting project, the important construction parameters such as slurry water-cement ratio, grouting pressure, and time are often judged by experience. Studying the flow of slurry in the fractured rock mass can guide onsite grouting and can aid in properly designing the grouting parameters [12]. A grouting project is of great significance. Therefore, it is becoming more and more important to study the characteristics of the slurry itself and the flow of the slurry in the rock mass [13].

Fracture is the medium into which the slurry flows in a rock mass, and the simplest type is the smooth parallel plate fracture. By studying the parallel plate fracture, the flow law of the slurry in the rock mass can be well grasped, so some 
scholars have studied this problem and have obtained a series of results. Among them, the cubic law [14-16] has been widely used because of its accuracy and simplicity. Through theoretical derivation, it is found that the cubic law can be obtained from the Navier-Stokes (N-S) equation $[17,18]$. To be precise, the cubic law is the theoretical solution of an incompressible Newtonian fluid doing steady laminar flow in smooth parallel fractures. However, grouting materials are mostly nonNewtonian fluids. Therefore, more flow equations have been proposed. Wereley and Pang [19] proposed a flow equation for the steady laminar flow of an incompressible Bingham fluid in smooth parallel fractures. Yan and Koplik [20] derived the flow equation of the steady laminar flow of an incompressible power law fluid in a smooth parallel fracture. Zou et al. [21] also obtained the flow equation of a Herschel-Bulkley (H-B) fluid which is more general.

The above models all have the same disadvantage, that is, they ignore the effect of inertial terms. In some cases, there is a large calculation error. In addition, at present, many grouting materials have a very short solidification time, ranging from a few seconds to a few tens of seconds, and the viscosity changes significantly with time, so it is necessary to take the inertial term into account in the equation derivation. There is a "flow core" when a Bingham fluid flows. Therefore, the unsteady flow equation of a Bingham fluid needs to be divided into two sections. The equation is complicated and difficult to solve. In this paper, the unsteady-state flow model between parallel plates of a Newtonian fluid considering inertial force is first derived. Combined with the relationship between the steady-state solution of a Bingham fluid and a Newtonian fluid, the approximate unsteady-state flow equation of a Bingham fluid suitable for describing slurry flow is constructed and the approximate solution is verified by numerical calculation. Then, based on the unsteady-state flow model, the calculation method of the flow distance of slurry in the fractures of smooth parallel plates is obtained, and the simplified condition of a Bingham fluid unsteady-state flow model is given. Finally, different models are used to calculate the mud diffusion distance under different conditions, and the correctness of the simplified conditions is also proven.

\section{Theoretical Model}

2.1. Steady-State Flow Model of Slurry in Fracture. Firstly, the steady-state flow equation is derived based on $2 \mathrm{D} \mathrm{N}-\mathrm{S}$ equations, and the coordinate system is shown in Figure 1. The derivation process is based on the following assumptions:

(1) The flow state of slurry is laminar flow

(2) The slurry is incompressible

(3) The grouting process has reached a stable state

(4) The property of slurry does not change during grouting

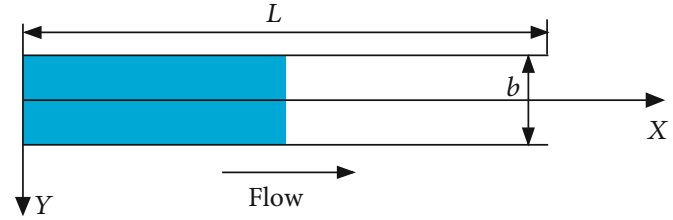

Figure 1: Diagram of a parallel plate fracture channel.

The differential equation of viscous fluid motion is expressed by stress:

$$
\left\{\begin{array}{l}
\frac{\partial u}{\partial t}+\frac{u \partial u}{\partial x}+\frac{v \partial u}{\partial y}=f_{x}+\frac{1}{\rho}\left(\frac{\partial p_{x x}}{\partial x}+\frac{\partial \tau_{x y}}{\partial y}\right) \\
\frac{\partial v}{\partial t}+\frac{u \partial v}{\partial x}+\frac{v \partial v}{\partial y}=f_{y}+\frac{1}{\rho}\left(\frac{\partial p_{y y}}{\partial y}+\frac{\partial \tau_{y x}}{\partial x}\right)
\end{array}\right.
$$

The constitutive equation of a Newtonian fluid is shown as follows:

$$
\left(\begin{array}{cc}
p_{x x} & \tau_{x y} \\
\tau_{y x} & p_{y y}
\end{array}\right)=\mu\left(\begin{array}{cc}
2 \frac{\partial u}{\partial x} & \frac{\partial u}{\partial y}+\frac{\partial v}{\partial x} \\
\frac{\partial v}{\partial x}+\frac{\partial u}{\partial y} & 2 \frac{\partial v}{\partial y}
\end{array}\right)-\left(\begin{array}{cc}
p & 0 \\
0 & p
\end{array}\right) .
$$

The continuity equation for incompressible fluids is shown as follows:

$$
\frac{\partial u}{\partial x}+\frac{\partial v}{\partial y}=0
$$

Bring equation (2) and equation (3) into equation (1) to obtain the N-S equation [22], and we have

$$
\left\{\begin{array}{l}
\frac{\partial u}{\partial t}+\frac{u \partial u}{\partial x}+\frac{v \partial u}{\partial y}=f_{x}-\frac{1}{\rho} \frac{\partial p}{\partial x}+\frac{\mu}{\rho}\left(\frac{\partial^{2} u}{\partial x^{2}}+\frac{\partial^{2} u}{\partial y^{2}}\right) \\
\frac{\partial v}{\partial t}+\frac{u \partial v}{\partial x}+\frac{v \partial v}{\partial y}=f_{y}+\frac{1}{\rho} \frac{\partial p}{\partial y}+\frac{\mu}{\rho}\left(\frac{\partial^{2} v}{\partial x^{2}}+\frac{\partial^{2} v}{\partial y^{2}}\right)
\end{array}\right.
$$

According to the four hypotheses mentioned above, we can get

$$
\begin{gathered}
v=0, \\
\frac{\partial v}{\partial x}=\frac{\partial v}{\partial y}=0, \\
\frac{\partial u}{\partial x}=0 .
\end{gathered}
$$

Therefore, the two-dimensional problem is simplified into a one-dimensional problem. The definite condition that 
makes it easy to get the problem is shown as follows:

$$
\begin{gathered}
\mu \frac{\partial^{2} u}{\partial y^{2}}+\frac{\Delta P}{L}=0, \\
\left.\frac{\partial u}{\partial y}\right|_{y=0}=0, \\
\left.u\right|_{y= \pm(b / 2)}=0 .
\end{gathered}
$$
follows:

The velocity distribution equation can be solved as

$$
u=\frac{b^{2}}{8 \mu} \frac{\Delta P}{L}\left[1-\left(\frac{2 y}{b}\right)^{2}\right]
$$

Integral along the $Y$ direction to obtain the average velocity equation, we have

$$
\bar{u}=\frac{1}{b} \int_{-(b / 2)}^{(b / 2)} u d y=-\frac{b^{2}}{12 \mu} \frac{\Delta P}{L} .
$$

Similarly, equations of the average velocity of a nonNewtonian fluid can be obtained. The average velocity equation of the steady flow of a Bingham fluid is shown as follows:

$\bar{u}=\frac{2}{b} \int_{y_{0}}^{(b / 2)} u d y+\left.b_{0} u\right|_{y=y_{0}}=-\frac{b^{2}}{12 \mu} \frac{\Delta P}{L}\left(1-\frac{b_{0}}{b}\right)^{2}\left(1+\frac{1}{2} \frac{b_{0}}{b}\right)$,

where $b_{0}=-\left(2 \tau_{0} L / \Delta p\right)$, which is the width of the "flow core," like Figure 2.

Similarly, for a power law fluid, when we calculate the steady-state flow equation of a power law fluid, we only need to replace the constitutive equation of the fluid $[4,20,23]$ :

$$
\begin{gathered}
\tau=K \dot{\gamma}^{n} \\
\dot{\gamma}=\frac{1}{2} \sqrt{4\left(\frac{\partial u}{\partial x}\right)^{2}+2\left(\frac{\partial u}{\partial y}+\frac{\partial v}{\partial x}\right)^{2}+4\left(\frac{\partial v}{\partial y}\right)^{2}}
\end{gathered}
$$

And then we can get,

$$
\begin{gathered}
K \frac{\partial}{\partial y}\left(\frac{\partial u}{\partial y}\right)^{n}+\frac{\Delta P}{L}=0, \\
\left.\frac{\partial u}{\partial y}\right|_{y=0}=0 \\
\left.u\right|_{y= \pm(b / 2)}=0 .
\end{gathered}
$$

It is not difficult to acquire the steady-state average velocity equation of a power law fluid:

$$
\bar{u}=-\frac{n}{4 n+2}\left(\frac{\Delta P}{2 K L}\right)^{(1 / n)} b^{(n+1 / n)}
$$

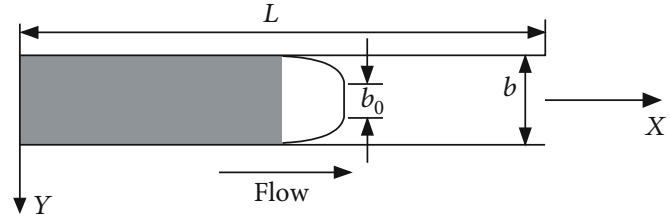

FIgURE 2: Velocity distribution of a Bingham fluid in a parallel plate fracture channel.

It is not easy to directly calculate the flow equation of an $\mathrm{H}-\mathrm{B}$ fluid by the N-S equation. Therefore, based on the relationship between this model and the constitutive equation of the model mentioned above, the flow equation of an H-B fluid is obtained by analogy. The average velocity equation obtained is consistent with the research results of other scholars $[21,24]$.

$\bar{u}=-\frac{n}{4 n+2}\left(\frac{\Delta P}{2 K L}\right)^{(1 / n)} b^{(n+1 / n)}\left(1-\frac{b_{0}}{b}\right)^{(n+1 / n)}\left(1+\frac{n}{n+1} \frac{b_{0}}{b}\right)$.

2.2. Unsteady Flow Model of Slurry in Fracture. The above formula is based on the assumption of stable flow. Next, we only keep assumptions (1), (2), and (4) to further derive the unsteady flow equation. The influence of inertia force must be taken into account in the establishment of unsteadystate equations. The first is the unsteady flow solution based on a Newtonian fluid:

$$
\begin{gathered}
\frac{\partial u}{\partial t}-\frac{\mu}{\rho} \frac{\partial^{2} u}{\partial y^{2}}=\frac{\Delta P}{\rho L}, \\
u(0, y)=u_{0}(y), \\
\frac{\partial u}{\partial y}(t, 0)=0, \\
u\left(t,-\frac{b}{2}\right)=u\left(t, \frac{b}{2}\right)=0 .
\end{gathered}
$$

Solving equation (14) is a pure mathematical process. First of all, it needs to be divided into two subproblems, and then the solutions of the two subproblems are superposed to get the original solution.

Subproblem 1.

$$
\begin{gathered}
\frac{\partial u}{\partial t}-\frac{\mu}{\rho} \frac{\partial^{2} u}{\partial y^{2}}=0, \\
u(0, y)=u_{0}(y), \\
\frac{\partial u}{\partial y}(t, 0)=0, \\
u\left(t,-\frac{b}{2}\right)=u\left(t, \frac{b}{2}\right)=0 .
\end{gathered}
$$




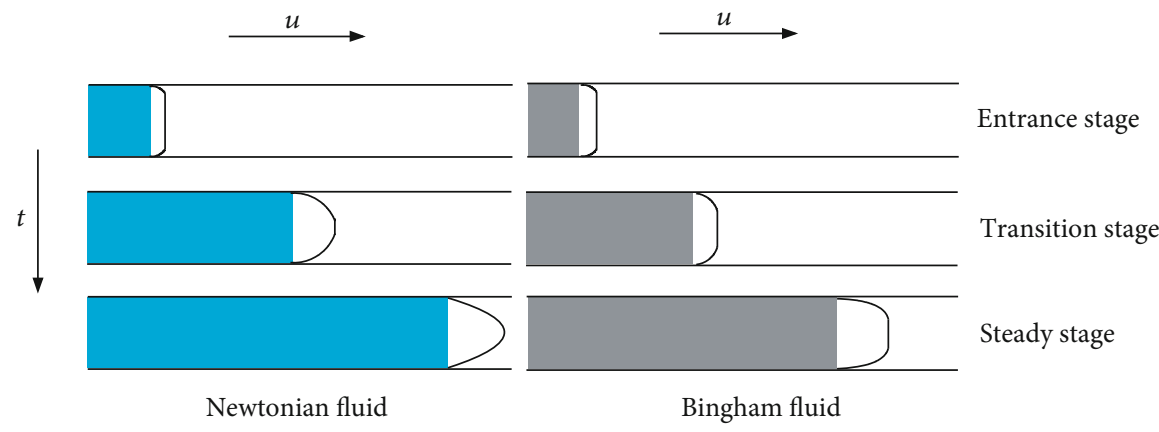

Figure 3: Distribution diagram of velocity in the entrance stage, the transition stage, and the steady stage when a Newtonian fluid and a Bingham fluid flow in fractures.

Subproblem 2.

$$
\begin{gathered}
\frac{\partial u}{\partial t}-\frac{\mu}{\rho} \frac{\partial^{2} u}{\partial y^{2}}=\frac{\Delta P}{\rho L}, \\
u(0, y)=0, \\
\frac{\partial u}{\partial y}(t, 0)=0, \\
u\left(t,-\frac{b}{2}\right)=u\left(t, \frac{b}{2}\right)=0 .
\end{gathered}
$$

The solution of Subproblem 1 is as follows:

$u_{1}(y, t)=\sum_{k=1}^{\infty} a_{k} e^{-(k \pi / b)^{2}(\mu / \rho) t} \sin \left(\frac{k \pi}{b} y+\frac{k \pi}{2}\right), \quad(k=1,2, \cdots)$,

where $a_{k}=(2 / b) \int_{-(b / 2)}^{(b / 2)} u_{0}(y) \sin ((k \pi / b) y+(k \pi / 2)) d x$.

The solution of Subproblem 2 is as follows:

$$
\begin{gathered}
u_{2}(y, t)=\frac{b^{2} \Delta P}{12 \mu L} \sum_{k=1}^{\infty} f_{Y}(y) f_{T}(t), \quad(k=1,2, \cdots) . \\
f_{Y}(y)=24\left(\frac{1}{k \pi}\right)^{3}\left[(-1)^{k+1}+1\right] \sin \left(\frac{k \pi}{b} y+\frac{k \pi}{2}\right), \\
f_{T}(t)=1-e^{-(k \pi / b)^{2}(\mu / \rho) t} .
\end{gathered}
$$

When the initial velocity $u_{0}(y)=0$ in Subproblem 1 , the solution of Subproblem 1 is always equal to 0 . Therefore, the solution of the original problem is equal to the solution of Subproblem 2.

$$
u_{\text {new }}(y, t)=u_{2}(y, t)
$$

According to equation (18), the unsteady solution of a Newtonian fluid flowing in parallel plates can be divided into three terms: the first term is the average velocity term representing the magnitude of the velocity, the second term is the velocity distribution term related to the coordinates, and the third is the time-dependent attenuation term.

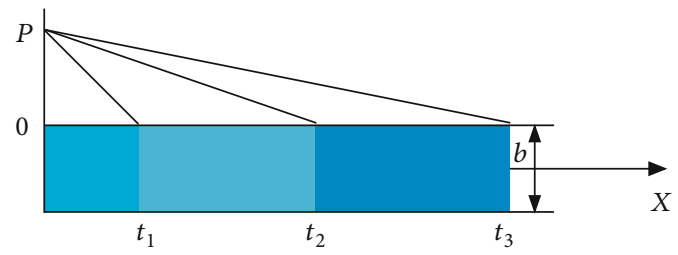

FIgURe 4: Pressure distribution diagram during grouting in a dry fracture.

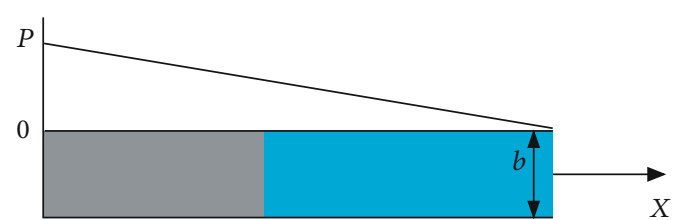

Figure 5: Schematic diagram of pressure distribution when grouting in water-saturated fractures.

TABLE 1: Fracture parameters and slurry parameters used in calculation.

\begin{tabular}{lccccc}
\hline $\begin{array}{l}\text { Injection } \\
\text { pressure } \\
(\mathrm{kPa})\end{array}$ & $\begin{array}{c}\text { Length } \\
(\mathrm{m})\end{array}$ & $\begin{array}{c}\text { Aperture } \\
(\mathrm{m})\end{array}$ & $\begin{array}{c}\text { Density } \\
\left(\mathrm{kg} / \mathrm{m}^{3}\right)\end{array}$ & $\begin{array}{c}\text { Plastic } \\
\text { viscosity } \\
(\mathrm{Pa} \cdot \mathrm{s})\end{array}$ & $\begin{array}{c}\text { Yield } \\
\text { stress } \\
(\mathrm{Pa})\end{array}$ \\
\hline 10 & 0.1 & 0.001 & 1540 & 0.014 & 0.94 \\
\hline
\end{tabular}

It is assumed that the time for a Newtonian fluid and a Bingham fluid to reach steady flow from 0 is the same. The unsteady flow equation of a Bingham fluid can be obtained by combining the relationship between the steady flow velocity equation of a Bingham fluid [25] and the steady solution of a Newtonian runny nose (equation (7)).

$$
\begin{gathered}
u_{\text {bin }}(y, t)=u_{\text {new }}(y, t) \cdot f_{\text {trans } 1}(y), \\
f_{\text {trans } 1}(y)=\frac{1-(2 y / b)^{2}-2\left(b_{0} / b\right)(1-(2|y| / b))}{1-(2 y / b)^{2}}, \\
\left(\frac{b_{0}}{2}<|y|<\frac{b}{2}\right) .
\end{gathered}
$$




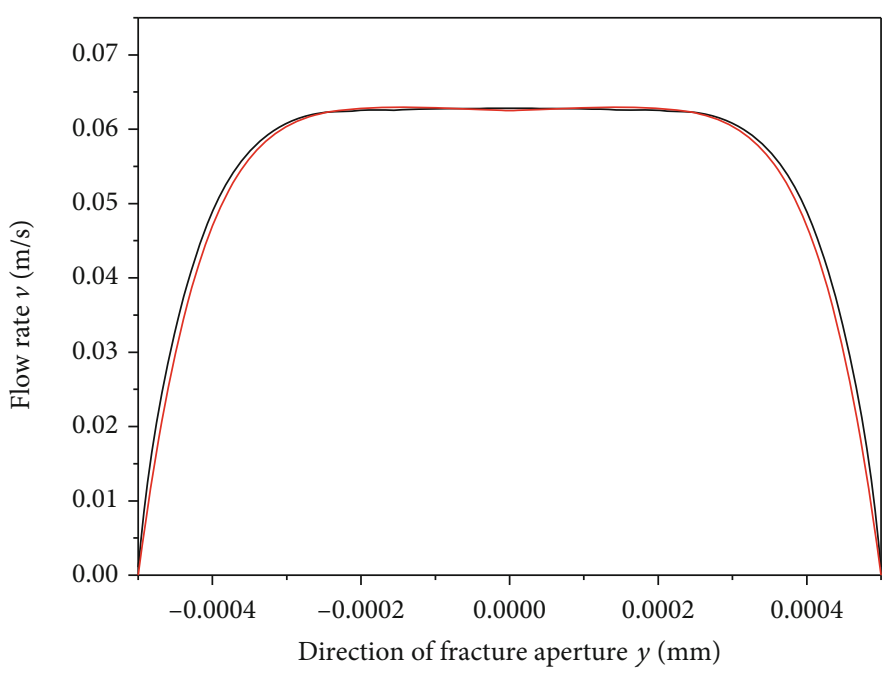

Numerical

Theoretical

(a) $t=0.001 \mathrm{~s}$

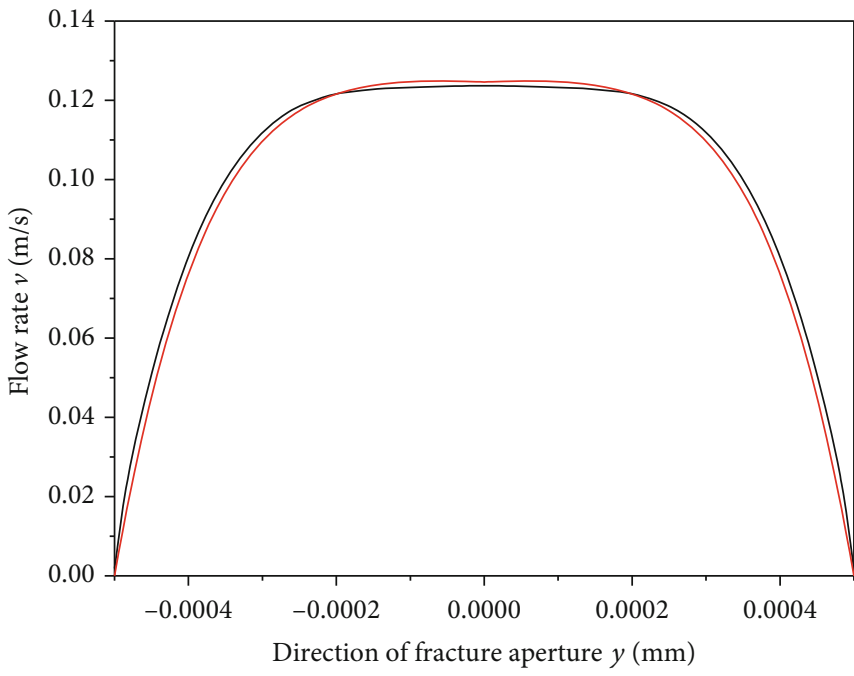

Numerical

Theoretical

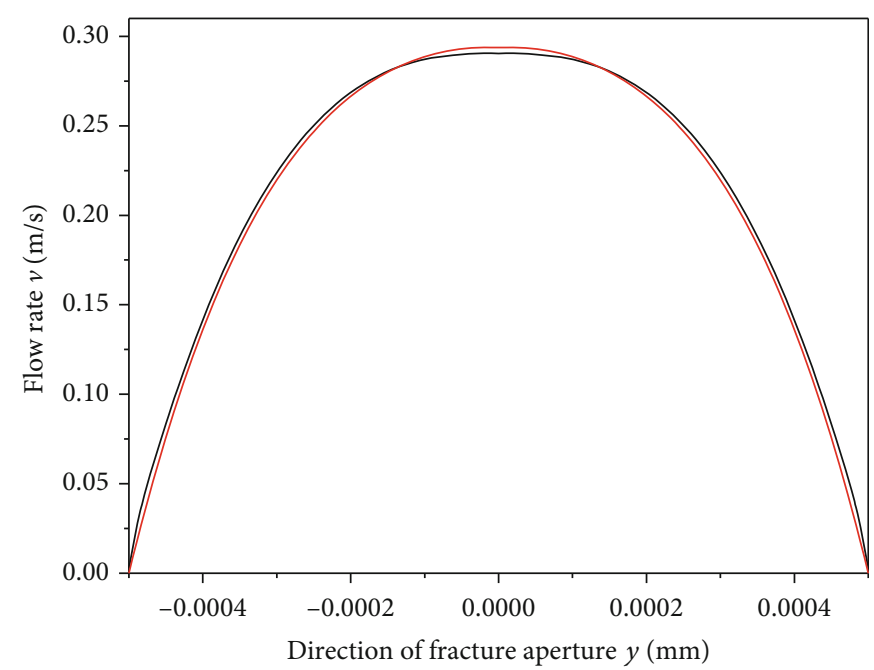

- Numerical

Theoretical

(c) $t=0.005 \mathrm{~s}$

(b) $t=0.002 \mathrm{~s}$

Figure 6: Continued. 


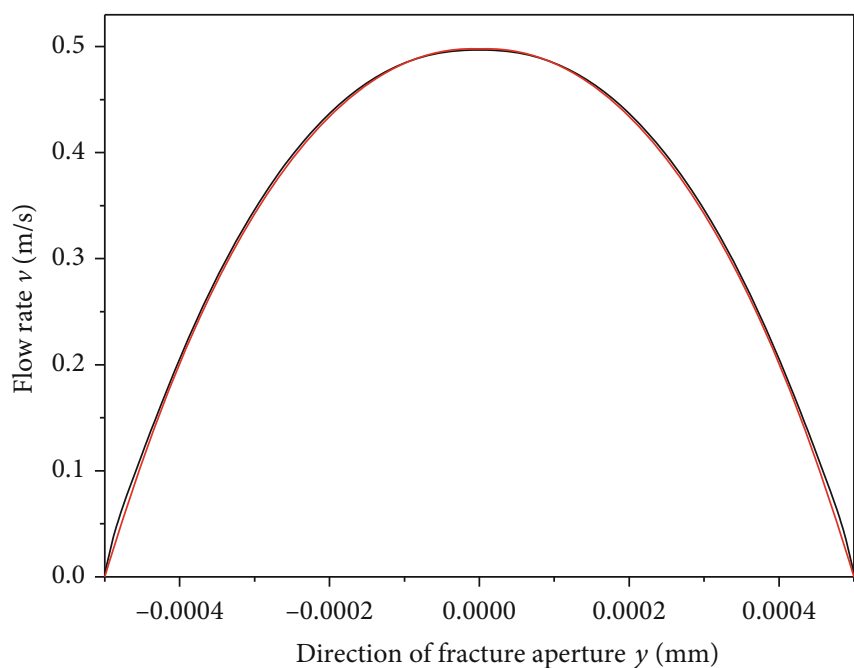

- Numerical Theoretical

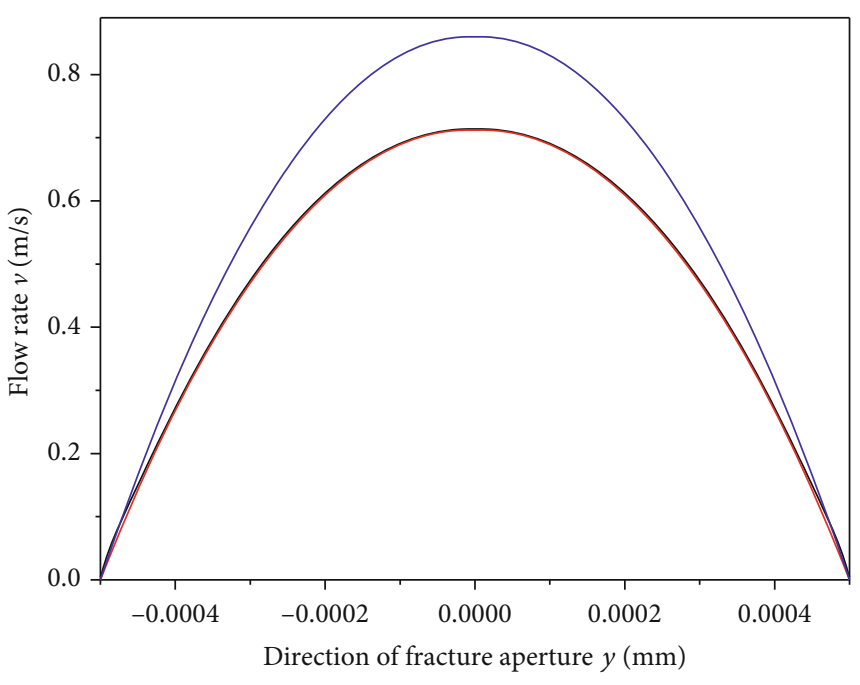

- Numerical

— Theoretical

_ Steady state

(d) $t=0.01 \mathrm{~s}$

(e) $t=0.02 \mathrm{~s}$

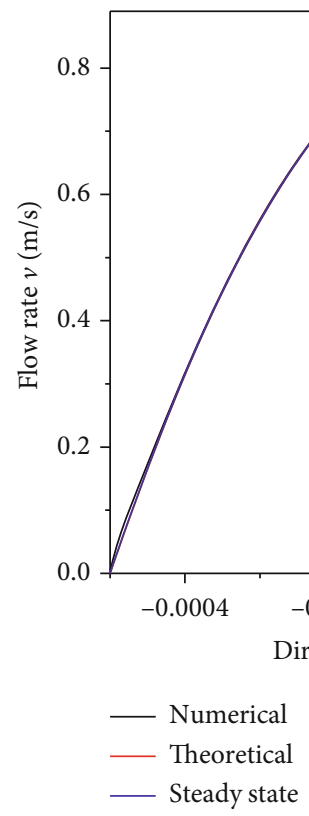

(f) $t=0.1 \mathrm{~s}$

FIGURE 6: Relationship between velocity distribution curve and time when slurry flows in fractures.

Through the unsteady solution of a Newtonian fluid and a Bingham fluid, we can get the fluid flow process in a parallel plate, which will go through the entrance stage, transition stage, and stable stage. The entrance stage is located at the entrance of the parallel plate, which is generally very short in length. In this stage, the boundary effect has not affected the whole flow layer, even for a Newtonian fluid; its velocity distribution will show a similar shape of "flow core." In the transition stage, the boundary effect has affected the whole flow layer, but the influence of inertial force has not disappeared, and the velocity distribution is still changing.
When it comes to the stable stage, the influence of the inertial term has disappeared, and the fluid enters a stable flow state (see Figure 3).

\section{Model Application and Simplification}

3.1. Model Application. The derivation of the unsteady flow solution of a Bingham fluid is not only to understand the flow pattern of the slurry in the fissure, but more importantly to obtain the parameters or methods that are of great significance to grouting engineering. 

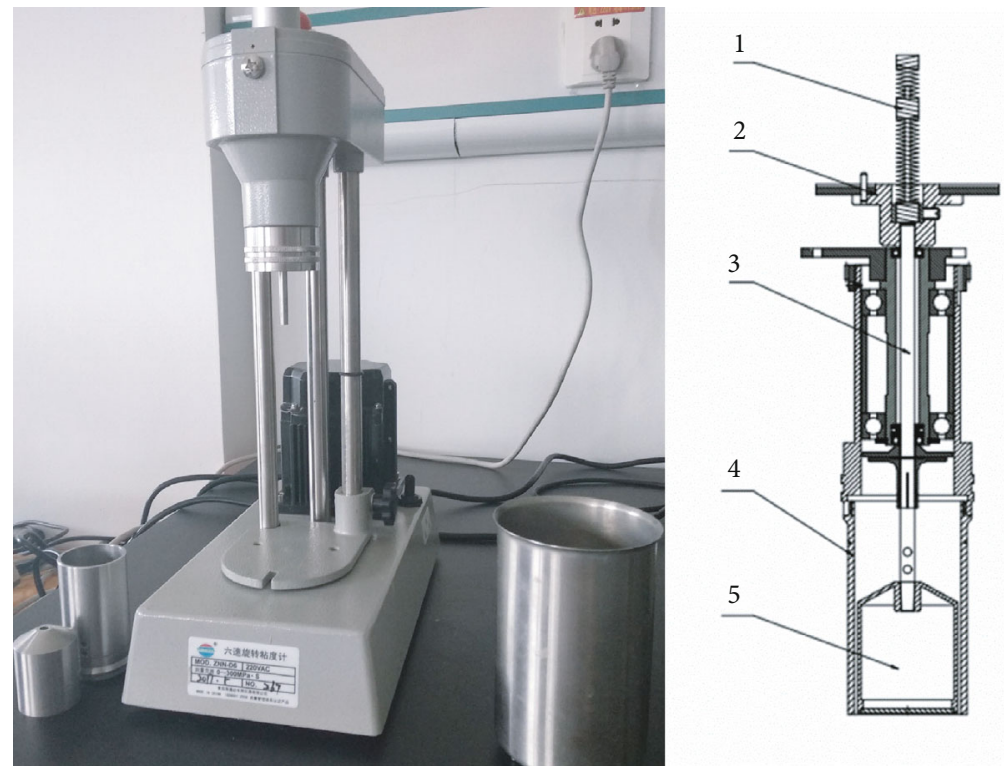

1. Spring assembly

2. Dial assembly

3. Inner cylinder shaft

4. External cylinder

5. Inner cylinder

FIGURE 7: ZNN-D6 viscometer physical figure and schematic diagram of key parts.

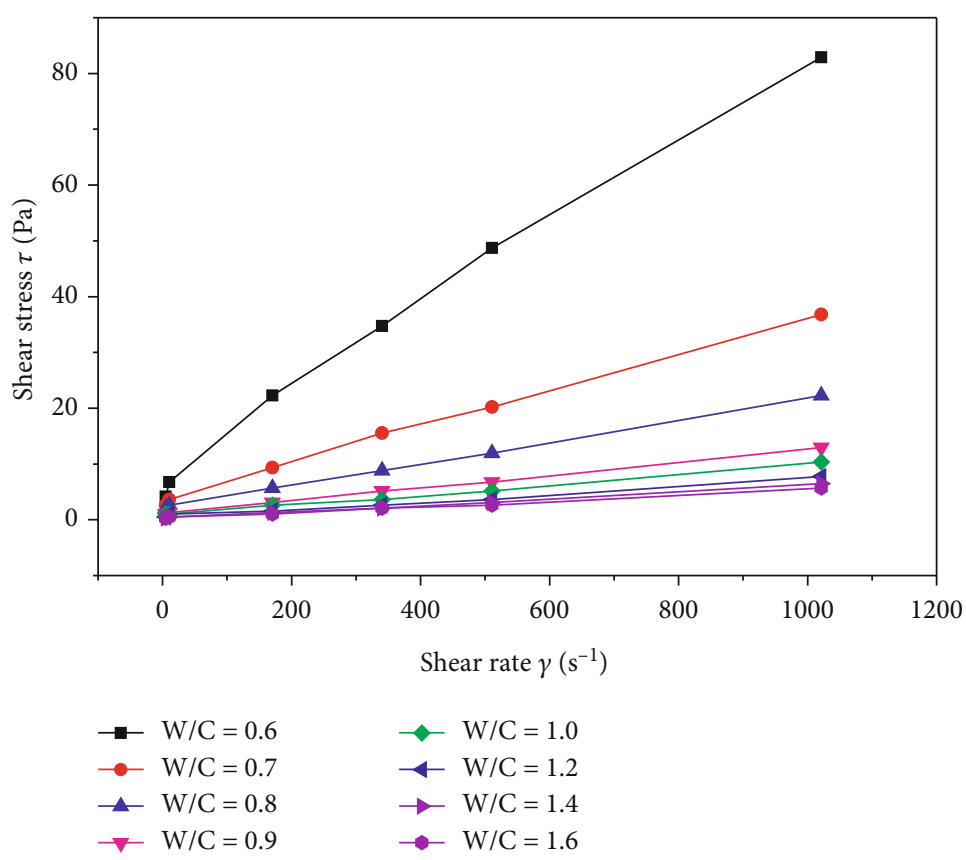

FIgURE 8: Rheological curves of ordinary Portland cement slurry with different water-cement ratios.

According to $b_{0}=-\left(2 \tau_{0} L / \Delta p\right)$, when $b_{0}=b$, the slurry will stop flowing. At this time, the critical pressure gradient is the starting pressure gradient of the slurry, and the critical length is the farthest distance that the slurry can reach in the fracture.

$$
\begin{aligned}
& \left(\frac{\Delta p}{L}\right)_{c r}=-\frac{2 \tau_{0}}{b}, \\
& L_{\max }=-\frac{\Delta p b}{2 \tau_{0}} .
\end{aligned}
$$

In addition, through further processing of the unsteadystate equation, the corresponding relationship between grouting time and slurry flow distance can be obtained. Also based on Newtonian fluids, equation (18) is integrated to obtain the average velocity:

$$
\bar{u}_{\text {new }}=\frac{1}{b} \int_{-(b / 2)}^{(b / 2)} u(y, t) d y=\frac{2 b^{2} \Delta P}{\mu I} \sum_{k=1}^{\infty}\left(\frac{1}{k \pi}\right)^{4}\left[(-1)^{k+1}+1\right]^{2} f_{T}(t) .
$$




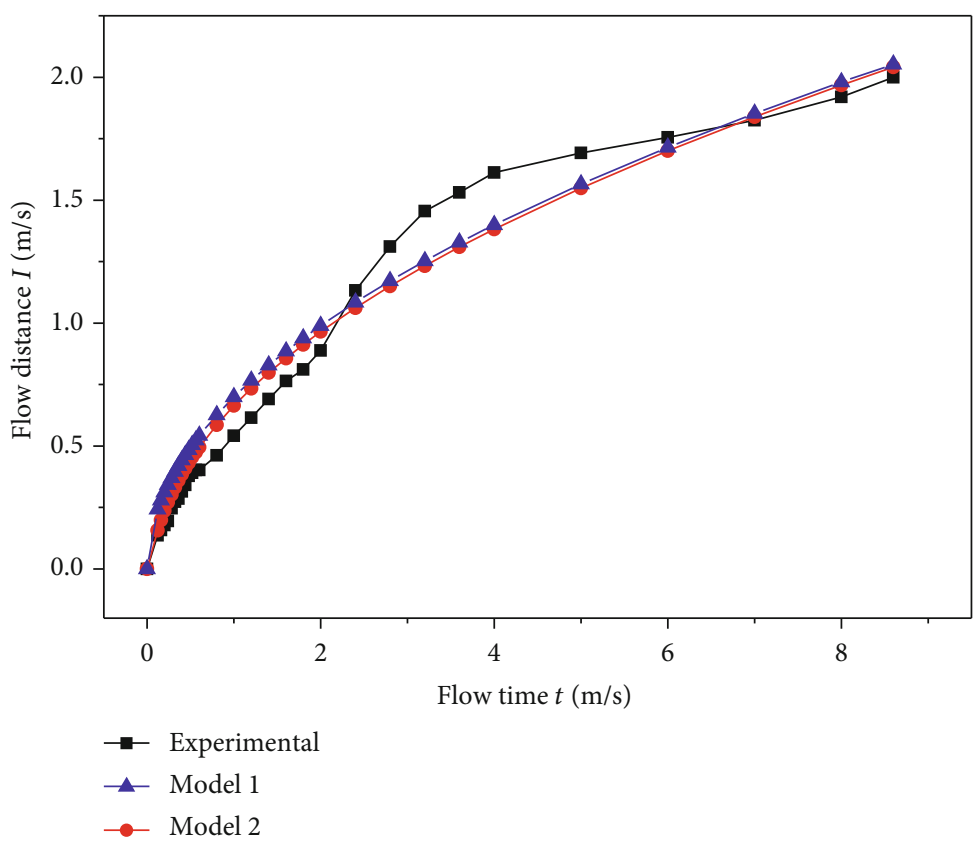

Figure 9: The relationship between flow time and flow distance when water flows in a fracture. Model 1 is the result of the iterative calculation of equation (8), and model 2 is the result of direct calculation using equation (26).

Since $\bar{u}=(d I / d t)[13]$, replace the left side of equation (25), which can be obtained after an integral operation:

$$
\begin{gathered}
I_{\text {new }}^{2}=\frac{4 b^{2} \Delta P}{\mu} \sum_{k=1}^{\infty}\left(\frac{1}{k \pi}\right)^{4}\left[(-1)^{k+1}+1\right]^{2} F_{T}(t), \\
F_{T}(t)=t+\left(\frac{b}{k \pi}\right)^{2} \frac{\rho}{\mu} e^{-(k \pi / b)^{2}(\mu / \rho) t}-\left(\frac{b}{k \pi}\right)^{2} \frac{\rho}{\mu} .
\end{gathered}
$$

According to the previous assumption, the average velocity of a Bingham fluid in the fracture is as follows:

$$
\begin{gathered}
\bar{u}_{\text {bin }}=f_{\text {trans } 2} \bar{u}_{\text {new }}, \\
f_{\text {trans } 2}=\left(1-\frac{b_{0}}{b}\right)^{2}\left(1+\frac{1}{2} \frac{b_{0}}{b}\right) .
\end{gathered}
$$

The relationship between time and distance of a Bingham flow in fractures is as follows:

$$
I_{\text {bin }}^{2}=f_{\text {trans } 2} \frac{4 b^{2} \Delta P}{\mu} \sum_{k=1}^{\infty}\left(\frac{1}{k \pi}\right)^{4}\left[(-1)^{k+1}+1\right]^{2} F_{T}(t) .
$$

In the differential calculation, approximate processing is also adopted. When integrating the flow distance $I$, ignoring $b_{0}$ will also change with $I$. Therefore, in the actual calculation, it is necessary to correct the value of $b_{0}$ by using an iterative method.

Although the relationship between the slurry flow time and the distance in the fracture has been obtained, it is necessary to distinguish fractures before calculation. Here, fractures are divided into dry fracture and water-saturated

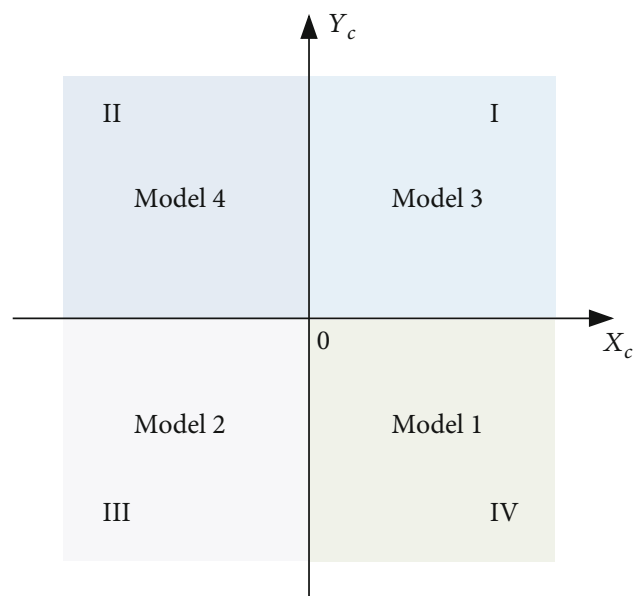

Figure 10: Schematic diagram of discrimination space.

fracture according to whether there is water in the fracture before grouting. Different types of fractures use slightly different equations to predict slurry diffusion.

First of all, for the dry fracture, it is considered that there is only air inside the fracture before grouting, and the air has high permeability and compressibility, so the influence of air on the slurry flow is not considered here, that is, the gasliquid two-phase flow is not considered. The traditional method is to use the steady-state flow equation of slurry for iterative calculation, but at the initial stage of slurry diffusion, the diffusion distance tends to zero, that is, the pressure gradient tends to infinity (see Figure 4), and the calculated velocity is also very large, so it is difficult to choose the appropriate initial iteration value. One method is to use reverse iteration 
TABLE 2: Calculation results of four models for slurry flow distance under different conditions.

\begin{tabular}{|c|c|c|c|c|c|c|}
\hline \multirow{2}{*}{ Aperture, $b(\mathrm{~mm})$} & \multirow{2}{*}{ Pressure, $P(\mathrm{MPa})$} & \multirow{2}{*}{ Time, $t(\mathrm{~s})$} & \multicolumn{4}{|c|}{ Diffusion distance, $I(\mathrm{~m})$} \\
\hline & & & Model 1 & Model 2 & Model 3 & Model 4 \\
\hline 0.1 & 0.1 & 0.01 & 0.0094 & 0.0093 & 0.0093 & 0.0093 \\
\hline 0.1 & 0.1 & 1 & 0.0937 & 0.0937 & 0.0908 & 0.0908 \\
\hline 0.1 & 0.1 & 100 & 0.9366 & 0.9366 & 0.6990 & 0.6990 \\
\hline 0.1 & 1 & 0.01 & 0.0296 & 0.0295 & 0.0296 & 0.0295 \\
\hline 0.1 & 1 & 1 & 0.2962 & 0.2962 & 0.2933 & 0.2933 \\
\hline 0.1 & 1 & 100 & 2.9617 & 2.9617 & 2.6899 & 2.6899 \\
\hline 0.1 & 10 & 0.01 & 0.0937 & 0.0933 & 0.0936 & 0.0932 \\
\hline 0.1 & 10 & 1 & 0.9366 & 0.9365 & 0.9337 & 0.9337 \\
\hline 0.1 & 10 & 100 & 9.3659 & 9.3658 & 9.0836 & 9.0835 \\
\hline 1 & 0.1 & 0.01 & 0.0937 & 0.0606 & 0.0934 & 0.0605 \\
\hline 1 & 0.1 & 1 & 0.9366 & 0.9326 & 0.9084 & 0.9046 \\
\hline 1 & 0.1 & 100 & 9.3659 & 9.3655 & 6.990 & 6.9898 \\
\hline 1 & 1 & 0.01 & 0.2962 & 0.1916 & 0.2959 & 0.1914 \\
\hline 1 & 1 & 1 & 2.9617 & 2.9492 & 2.9332 & 2.9209 \\
\hline 1 & 1 & 100 & 29.6174 & 29.6162 & 26.8995 & 26.8984 \\
\hline 1 & 10 & 0.01 & 0.9366 & 0.6058 & 0.9363 & 0.6057 \\
\hline 1 & 10 & 1 & 9.3659 & 9.3263 & 9.3372 & 9.2979 \\
\hline 1 & 10 & 100 & 93.6586 & 93.6546 & 90.8355 & 90.8318 \\
\hline 10 & 0.1 & 0.01 & 0.9366 & 0.0774 & 0.9337 & 0.0774 \\
\hline 10 & 0.1 & 1 & 9.3659 & 6.0578 & 9.0836 & 5.9391 \\
\hline 10 & 0.1 & 100 & 93.6586 & 93.2633 & 69.9001 & 69.6849 \\
\hline 10 & 1 & 0.01 & 2.9617 & 0.2447 & 2.9589 & 0.2447 \\
\hline 10 & 1 & 1 & 29.6174 & 19.1566 & 29.3320 & 19.0370 \\
\hline 10 & 1 & 100 & 296.1744 & 294.9246 & 268.9949 & 267.9673 \\
\hline 10 & 10 & 0.01 & 9.3659 & 0.7739 & 9.3630 & 0.7739 \\
\hline 10 & 10 & 1 & 93.6586 & 60.5785 & 93.3722 & 60.4586 \\
\hline 10 & 10 & 100 & 936.5858 & 932.6333 & 908.3553 & 904.6386 \\
\hline
\end{tabular}

[26]. Take cubic law as an example, the iteration formula is as follows:

$$
\begin{gathered}
I_{n}=I_{n+1}-\bar{u}_{n+1}\left(t_{n+1}-t_{n}\right), \\
\bar{u}_{n+1}=\frac{\Delta P b^{2}}{12 \mu I_{n+1}} .
\end{gathered}
$$

When the fracture water is saturated, it is assumed that both the slurry and the water are incompressible. Since the pressure ladder will not decrease with the increase of the diffusion distance (see Figure 5), the diffusion distance of the slurry can be directly calculated as follows:

$$
I_{\text {bin }}=\int_{0}^{t} \bar{u}_{\text {bin }}(\tau) d \tau=f_{\text {trans } 2} \frac{2 b^{2} \Delta P}{\mu L} \sum_{k=1}^{\infty}\left(\frac{1}{k \pi}\right)^{4}\left[(-1)^{k+1}+1\right]^{2} F_{T}(t) .
$$

3.2. Simplified Conditions. It can be seen from equation (19) that the attenuation coefficient in the timedependent attenuation term is inversely proportional to the square of fracture opening, inversely proportional to the density of slurry, and directly proportional to the viscosity of slurry. The development trend of grouting materials is that the viscosity of slurry is decreasing and the density is increasing, which leads to an increase in the time it takes for the slurry to reach steady flow. Especially for the fractures with a large opening, the influence of inertia force cannot be ignored, and the grouting time and flow distance calculated by the steady-state formula are no longer applicable. According to the formula calculation, for the centimeter fracture, it takes nearly $60 \mathrm{~s}$ for the slurry to reach the stable state. In the process of coal mining, the grouting time often used for roadway reinforcement is about 200-300 s, which also shows that the influence of inertia force cannot be ignored.

When using the Bingham fluid unsteady flow equation to calculate the flow distance of slurry in the fracture, the relative error is ensured to be less than $5 \%$, and the following simplified condition is obtained:

$$
\frac{\mu t}{\rho b^{2}} \geq 0.3035
$$


TABLe 3: Applicability of the first three models.

\begin{tabular}{|c|c|c|c|c|c|}
\hline \multirow{2}{*}{$\begin{array}{l}\text { Aperture, } b \\
(\mathrm{~mm})\end{array}$} & \multirow{2}{*}{$\begin{array}{l}\text { Pressure, } P \\
\quad(\mathrm{MPa})\end{array}$} & \multirow[b]{2}{*}{$\begin{array}{c}\text { Time, } t \\
\text { (s) }\end{array}$} & \multicolumn{3}{|c|}{ Relative error } \\
\hline & & & $\begin{array}{c}\text { Model } \\
1\end{array}$ & $\begin{array}{c}\text { Model } \\
2\end{array}$ & $\begin{array}{c}\text { Model } \\
3\end{array}$ \\
\hline 0.1 & 0.1 & 0.01 & $\sqrt{ }$ & $\sqrt{ }$ & $\sqrt{ }$ \\
\hline 0.1 & 0.1 & 1 & $\sqrt{ }$ & $\sqrt{ }$ & $\sqrt{ }$ \\
\hline 0.1 & 0.1 & 100 & $x$ & $x$ & $\sqrt{ }$ \\
\hline 0.1 & 1 & 0.01 & $\sqrt{ }$ & $\sqrt{ }$ & $\sqrt{ }$ \\
\hline 0.1 & 1 & 1 & $\sqrt{ }$ & $\sqrt{ }$ & $\sqrt{ }$ \\
\hline 0.1 & 1 & 100 & $x$ & $x$ & $\sqrt{ }$ \\
\hline 0.1 & 10 & 0.01 & $\sqrt{ }$ & $\sqrt{ }$ & $\sqrt{ }$ \\
\hline 0.1 & 10 & 1 & $\sqrt{ }$ & $\sqrt{ }$ & $\sqrt{ }$ \\
\hline 0.1 & 10 & 100 & $\sqrt{ }$ & $\sqrt{ }$ & $\sqrt{ }$ \\
\hline 1 & 0.1 & 0.01 & $x$ & $\sqrt{ }$ & $x$ \\
\hline 1 & 0.1 & 1 & $\sqrt{ }$ & $\sqrt{ }$ & $\sqrt{ }$ \\
\hline 1 & 0.1 & 100 & $x$ & $x$ & $\sqrt{ }$ \\
\hline 1 & 1 & 0.01 & $x$ & $\sqrt{ }$ & $x$ \\
\hline 1 & 1 & 1 & $\sqrt{ }$ & $\sqrt{ }$ & $\sqrt{ }$ \\
\hline 1 & 1 & 100 & $x$ & $x$ & $\sqrt{ }$ \\
\hline 1 & 10 & 0.01 & $x$ & $\sqrt{ }$ & $x$ \\
\hline 1 & 10 & 1 & $\sqrt{ }$ & $\sqrt{ }$ & $\sqrt{ }$ \\
\hline 1 & 10 & 100 & $\sqrt{ }$ & $\sqrt{ }$ & $\sqrt{ }$ \\
\hline 10 & 0.1 & 0.01 & $x$ & $\sqrt{ }$ & $x$ \\
\hline 10 & 0.1 & 1 & $x$ & $\sqrt{ }$ & $x$ \\
\hline 10 & 0.1 & 100 & $x$ & $x$ & $\sqrt{ }$ \\
\hline 10 & 1 & 0.01 & $x$ & $\sqrt{ }$ & $x$ \\
\hline 10 & 1 & 1 & $x$ & $\sqrt{ }$ & $x$ \\
\hline 10 & 1 & 100 & $x$ & $x$ & $\sqrt{ }$ \\
\hline 10 & 10 & 0.01 & $x$ & $\sqrt{ }$ & $x$ \\
\hline 10 & 10 & 1 & $x$ & $\sqrt{ }$ & $x$ \\
\hline 10 & 10 & 100 & $\sqrt{ }$ & $\sqrt{ }$ & $\sqrt{ }$ \\
\hline
\end{tabular}

Note: if the relative error is less than $5 \%$, it is $\sqrt{ }$, otherwise it is $\times$.

The time-dependent terms of the non-steady-state model quickly decay to 0 , and they can be replaced by those of the steady-state model:

$$
\tau_{0} \sqrt{\frac{t}{-3 \mu \Delta P}} \leq 0.062
$$

The size of the "flow core" is negligible with respect to the fracture opening, so the Newtonian fluid model can be used instead of the Bingham fluid model.

\section{Results and Verification}

4.1. Numerical Simulation of Bingham Fluid Flow in Fracture. The numerical calculation results are compared with the calculation results of equation (21). The fracture and slurry parameters selected here [27] are shown in Table 1.

According to the calculation results (see Figure 6), firstly, the approximate solution of the unsteady flow of a Bingham fluid between parallel plates obtained in this paper is highly consistent with the numerical results. Secondly, it also shows that the three stages of velocity distribution mentioned above do exist. It needs to be explained that in the stable stage, the velocity distribution does not observe "flow core," because the size of "flow core" $\left(b_{0}=1.88 e-5 \mathrm{~m}\right)$ is too small relative to the fracture opening.

\subsection{Related Tests}

4.2.1. Rheological Property Test of Cement Slurry. In order to study the flow law of a slurry, the first step is to study the flow characteristics of the slurry itself, that is, the rheology of the slurry [28-30]. The commonly used rheological models of slurry include the Newtonian fluid model, the Bingham fluid model, the power law fluid model, and the H-B fluid model. In this paper, a ZNN-D6 rotational viscometer (see Figure 7) is used to test the rheological property of ordinary Portland cement (OPC) slurry, and the rheological curves of the OPC slurry under different water-cement ratios are obtained (see Figure 8). When the water-cement ratio (W/C) of the cement slurry is more than 0.7 but less than 1.0, the rheological curve is basically straight and the intercept between the curve and coordinate $Y$ axis is obviously not zero, that is to say, there is yield stress. Therefore, we think that the water-cement slurry is more suitable for the Bingham fluid model than the OPC slurry with W/C of $0.7 \sim 1.0$, which is also consistent with the research of other scholars [31]. In the subsequent calculation of the slurry flow distance under different conditions, the slurry parameters of $\mathrm{W} / \mathrm{C}=0.8$ in this experiment are selected.

4.2.2. Experiment of Unsteady Fracture Flow of Water. In the derivation of the relationship between the diffusion distance and time of slurry, the differential relationship of $\bar{u}=d I / d t$ is adopted, so in order to verify equation (26), the experiment of water flowing in the parallel plate fracture is designed. After processing the experimental data, the results obtained and the theoretical calculation results are drawn in Figure 9, which prove the correctness of the differential relationship. At the same time, the correctness of equation (29) can also be guaranteed.

4.3. Application of Simplified Conditions. Based on formulas (23) and (24), we design two discriminant conditions $X_{c}$ and $Y_{c}$ :

$$
\begin{gathered}
X_{c}=\frac{\mu t}{\rho b^{2}}-0.3035, \\
Y_{c}=\tau_{0} \sqrt{\frac{t}{-3 \mu \Delta P}}-0.062 .
\end{gathered}
$$

According to the discriminant conditions, the discriminant space corresponding to the model can be divided into four quadrants (see Figure 10). According to the previous analysis, the entire space can be calculated using model 4 , but when the discriminant conditions $\left(X_{c}, Y_{c}\right)$ fall in quadrant II, only model 4 can be 
TABlE 4: Discriminant coordinates obtained under different conditions and their quadrants in the discriminant plane.

\begin{tabular}{|c|c|c|c|c|}
\hline $\begin{array}{l}\text { Aperture, } b \\
(\mathrm{~mm})\end{array}$ & $\begin{array}{l}\text { Pressure, } P \\
\quad(\mathrm{MPa})\end{array}$ & $\begin{array}{c}\text { Time, } t \\
(\mathrm{~s})\end{array}$ & $\begin{array}{c}\text { Discriminant } \\
\text { coordinates }\end{array}$ & Quadrant \\
\hline 0.1 & 0.1 & 0.01 & $\begin{array}{c}(11.5715, \\
-0.0591)\end{array}$ & IV \\
\hline 0.1 & 0.1 & 1 & $(1187.2,-0.0331)$ & IV \\
\hline 0.1 & 0.1 & 100 & $(118750,0.2267)$ & I \\
\hline 0.1 & 1 & 0.01 & $\begin{array}{l}(11.5715 \\
-0.0611)\end{array}$ & IV \\
\hline 0.1 & 1 & 1 & $(1187.2,-0.0529)$ & IV \\
\hline 0.1 & 1 & 100 & $(118750,0.0293)$ & I \\
\hline 0.1 & 10 & 0.01 & $\begin{array}{c}(11.5715 \\
-0.0617)\end{array}$ & IV \\
\hline 0.1 & 10 & 1 & $(1187.2,-0.0591)$ & IV \\
\hline 0.1 & 10 & 100 & $(118750,-0.0331)$ & IV \\
\hline 1 & 0.1 & 0.01 & $\begin{array}{l}(-0.1847 \\
-0.0591)\end{array}$ & III \\
\hline 1 & 0.1 & 1 & $\begin{array}{l}(11.5715 \\
-0.0331)\end{array}$ & IV \\
\hline 1 & 0.1 & 100 & $(1187.2,0.2267)$ & I \\
\hline 1 & 1 & 0.01 & $\begin{array}{l}(-0.1847 \\
-0.0611)\end{array}$ & III \\
\hline 1 & 1 & 1 & $\begin{array}{l}(11.5715 \\
-0.0529)\end{array}$ & IV \\
\hline 1 & 1 & 100 & $(1187.2,0.0293)$ & I \\
\hline 1 & 10 & 0.01 & $\begin{array}{l}(-0.1847 \\
-0.0617)\end{array}$ & III \\
\hline 1 & 10 & 1 & $\begin{array}{c}(11.5715 \\
-0.0591)\end{array}$ & IV \\
\hline 1 & 10 & 100 & $(1187.2,-0.0331)$ & IV \\
\hline 10 & 0.1 & 0.01 & $\begin{array}{l}(-0.3023 \\
-0.0591)\end{array}$ & III \\
\hline 10 & 0.1 & 1 & $\begin{array}{c}(-0.18475 \\
-0.0331)\end{array}$ & III \\
\hline 10 & 0.1 & 100 & $(11.5715,0.2267)$ & I \\
\hline 10 & 1 & 0.01 & $\begin{array}{l}(-0.3023 \\
-0.0611)\end{array}$ & III \\
\hline 10 & 1 & 1 & $\begin{array}{c}(-0.18475 \\
-0.0529)\end{array}$ & III \\
\hline 10 & 1 & 100 & $(11.5715,0.0293)$ & I \\
\hline 10 & 10 & 0.01 & $\begin{array}{l}(-0.3023 \\
-0.0617)\end{array}$ & III \\
\hline 10 & 10 & 1 & $\begin{array}{l}(-0.18475 \\
-0.0591)\end{array}$ & III \\
\hline 10 & 10 & 100 & $\begin{array}{c}(11.5715 \\
-0.0331)\end{array}$ & IV \\
\hline
\end{tabular}

used for calculation (to ensure that the model error is within 5\%); when the discriminant conditions $\left(X_{c}, Y_{c}\right)$ fall into quadrant IV, all four models can guarantee relatively high accuracy; when the discriminant conditions $\left(X_{c}, Y_{c}\right)$ fall in quadrant II, model 2 can be used for approximate calculation; finally, when the judgment condition $\left(X_{c}, Y_{c}\right)$ is in quadrant $\mathrm{I}$, model 3 can be used for approximate calculation.

In order to further verify the feasibility of the criteria, using the experimentally obtained cement slurry with W/C $=0.8$, plastic viscosity is 0.019 , yield stress is 2.18 , and density is 1600 . The slurry flow distance under different conditions is calculated. Among them, model 1 represents the steady-state Newtonian fluid (equation (8)), model 2 represents the unsteady-state Newtonian fluid (equation (26)), model 3 refers to the steady-state Bingham fluid (equation (9)), and model 4 represents the unsteady-state Bingham fluid (equation (29). The calculation results are shown in Table 2.

Taking model 4 as the standard, first judge its applicability based on the relative errors of the other three models (see Table 3), and then calculate the discriminant coordinates under different conditions to get Table 4 through the comparison table. The results in Tables 3 and 4 verify the accuracy of the discrimination method.

\section{Conclusion}

The unsteady flow equation of a Newtonian fluid in a parallel plate fracture is derived in detail based on the N-S equation. Combining the steady-state flow equations of a Newtonian fluid and a Bingham fluid, the unsteady-state flow equation of a Bingham fluid which is more suitable for describing slurry flow is constructed. The application conditions of the new model are analyzed. We can get the following conclusions:

(1) We have deduced the relationship between the flow time and flow distance of a Bingham fluid in the parallel plate fractures, and proved the accuracy of the derivation process through experiments

(2) The unsteady flow equation of a Bingham fluid makes up for the traditional model's inability to consider the influence of inertial forces on the calculation results, and the slurry flow velocity distribution is divided into the inlet section, the transition section, and the stable section through calculation

(3) We have provided the judgment condition that the unsteady flow equation of a Bingham fluid simplifies the traditional model. After bringing in the calculation criterion of specific construction parameters, we choose whether to use the traditional model and which model to use

The flow equations of power law fluids and $\mathrm{H}-\mathrm{B}$ fluids can be calculated with reference to the proposed ideas, which can be used for the flow calculation of a high water-cement ratio slurry. In future research, the effect of fracture roughness and tortuosity on slurry flow should also be studied. At the same time, changes in the rheology of the cement slurry over time should be considered. 


\section{Abbreviations}

$u, v: \quad$ Flow velocity of fluid in $x$ and $y$ directions

$p, \tau$ : Area force acting on fluid microelements

$f_{x}, f_{y}$ : Volume force acting on fluid microelements

$\mu$ : $\quad$ Newtonian fluid viscosity, corresponding to the

plastic viscosity of a Bingham fluid

$\rho: \quad$ Fluid density

$L: \quad$ Length of the fracture

$b$ : Aperture of the fracture

$b_{0}$ : The width of the "flow core"

$\Delta P: \quad$ Pressure difference across the fracture

$K$ : $\quad$ Consistency coefficient of a power law fluid and a Herschel-Bulkley fluid

$\dot{\gamma}: \quad$ Shear rate

$n$ : $\quad$ The rheological index of a power law fluid and a Herschel-Bulkley fluid

I: $\quad$ The flow distance of the fluid in the fracture at a certain moment (the length from the end of the fluid to the inlet).

\section{Data Availability}

The raw/processed data required to reproduce these findings cannot be shared at this time as the data also forms part of an ongoing study.

\section{Conflicts of Interest}

The authors declare that they have no conflicts of interest.

\section{References}

[1] L. Sun, H. Wu, B. Yang, and Q. Li, "Support failure of a highstress soft-rock roadway in deep coal mine and the equalized yielding support technology: a case study," International Journal of Coal Science \& Technology, vol. 2, no. 4, pp. 279-286, 2015.

[2] H. Wang, C. Jiang, P. Zheng, W. Zhao, and N. Li, “A combined supporting system based on filled-wall method for semi coalrock roadways with large deformations," Tunnelling and Underground Space Technology, vol. 99, article 103382, 2020.

[3] Y. Wang, B. Liu, and Y. Qi, "A risk evaluation method with an improved scale for tunnel engineering," Arabian Journal for Science and Engineering, vol. 43, no. 4, pp. 2053-2067, 2018.

[4] Y. Wang, C. Shu, L. M. Yang, and H. Z. Yuan, "A decoupling multiple-relaxation-time lattice Boltzmann flux solver for non-Newtonian power-law fluid flows," Journal of NonNewtonian Fluid Mechanics, vol. 235, pp. 20-28, 2016.

[5] Z. P. Li, S. C. Li, Q. S. Zhang et al., "Study on parameters of grouting reinforced circle for water-rich and soft fault fracture zone in tunnel," Applied Mechanics and Materials, vol. 470, pp. 925-929, 2013.

[6] J. Yang, C. Zhang, J. Fu, S. Wang, X. Ou, and Y. Xie, "Pregrouting reinforcement of underwater karst area for shield tunneling passing through Xiangjiang River in Changsha, China," Tunnelling and Underground Space Technology, vol. 100, article 103380, 2020.

[7] M. Zhu, X. Gong, X. Gao, S. Liu, and J. Yan, "Remediation of damaged shield tunnel using grouting technique: serviceability improvements and prevention of potential risks," Journal of
Performance of Constructed Facilities, vol. 33, no. 6, p. 04019062, 2019.

[8] G. Dai, Y. Sheng, S. Li, and Y. Zhang, "Experimental study on mechanical properties of anti-seepage slurry in landfill," Modern Physics Letters B, vol. 32, no. 34n36, p. 1840065, 2019.

[9] K. N. Zhang, Y. G. Chen, F. Y. Deng, and Q. Y. Tian, "Retention of clay-solidified grouting curtain to $\mathrm{Cd} 2+, \mathrm{Pb} 2+$ and $\mathrm{Hg} 2+$ in landfill of municipal solid waste," Journal of Central South University of Technology, vol. 11, no. 4, pp. 419-422, 2004.

[10] N. C. Collier, K. P. Travis, F. G. Gibb, and N. B. Milestone, "Characteristics of cementitious paste for use in deep borehole disposal of spent fuel and high level wasteforms," MRS Proceedings, vol. 1744, pp. 205-210, 2015.

[11] H. Eichhorn, "Industrial complex for solid radwaste management (ICSRM) at Chernobyl nuclear power plant functionality of the facilities. Factors of success," Atw. Internationale Zeitschrift fuer Kernenergie, vol. 57, no. 2, pp. 105-107, 2011.

[12] M. Axelsson and G. Gustafson, "A robust method to determine the shear strength of cement-based injection grouts in the field," Tunnelling and Underground Space Technology, vol. 21, no. 5, pp. 499-503, 2006.

[13] H. M. Kim, J. W. Lee, M. Yazdani, E. Tohidi, H. R. Nejati, and E. S. Park, "Coupled viscous fluid flow and joint deformation analysis for grout injection in a rock joint," Rock Mechanics and Rock Engineering, vol. 51, no. 2, pp. 627-638, 2018.

[14] S. Denetto and A. M. Kamp, "Cubic law evaluation using well test analysis for fractured reservoir characterization," in SPE Annual Technical Conference and Exhibition, Society of Petroleum Engineers, 2016.

[15] J. Funehag and Å. Fransson, "Sealing narrow fractures with a Newtonian fluid: model prediction for grouting verified by field study," Tunnelling and Underground Space Technology, vol. 21, no. 5, pp. 492-498, 2006.

[16] P. A. Witherspoon, J. S. Wang, K. Iwai, and J. E. Gale, "Validity of cubic law for fluid flow in a deformable rock fracture," Water Resources Research, vol. 16, no. 6, pp. 1016-1024, 1980.

[17] N. Weng, Q. Wang, J. Li, J. Lyu, H. Zhang, and W. Yao, "Liquid penetration in metal wire mesh between parallel plates under normal gravity and microgravity conditions," Applied Thermal Engineering, vol. 167, p. 114722, 2020.

[18] R. W. Zimmerman and I. W. Yeo, "Fluid flow in rock fractures: from the Navier-Stokes equations to the cubic law," Geophysical Monograph-American Geophysical Union, vol. 122, pp. 213-224, 2000.

[19] N. M. Wereley and L. Pang, "Nondimensional analysis of semi-active electrorheological and magnetorheological dampers using approximate parallel plate models," Smart Materials and Structures, vol. 7, no. 5, pp. 732-743, 1998.

[20] Y. Yan and J. Koplik, "Flow of power-law fluids in self-affine fracture channels," Physical Review E, vol. 77, no. 3, article 036315, 2008.

[21] L. Zou, U. Hakansson, and V. Cvetkovic, "Yield-power-law fluid propagation in water-saturated fracture networks with application to rock grouting," Tunnelling and Underground Space Technology, vol. 95, p. 103170, 2020.

[22] A. G. Petrov and I. S. Kharlamova, "The solutions of NavierStokes equations in squeezing flow between parallel plates," European Journal of Mechanics - B/Fluids, vol. 48, pp. 40-48, 2014.

[23] A. R. De Castro and M. Agnaou, "Numerical investigation of the apparent viscosity dependence on Darcy velocity during 
the flow of shear-thinning fluids in porous media," Transport in Porous Media, vol. 129, no. 1, pp. 93-120, 2019.

[24] S. G. Cherny and V. N. Lapin, "3D model of hydraulic fracture with Herschel-Bulkley compressible fluid pumping," Procedia Structural Integrity, vol. 2, pp. 2479-2486, 2016.

[25] L. Zou, U. Hakansson, and V. Cvetkovic, "Cement grout propagation in two-dimensional fracture networks: impact of structure and hydraulic variability," International Journal of Rock Mechanics and Mining Sciences, vol. 115, pp. 1-10, 2019.

[26] F. Xiao, Z. Zhao, and H. Chen, "A simplified model for predicting grout flow in fracture channels," Tunnelling and Underground Space Technology, vol. 70, pp. 11-18, 2017.

[27] M. Eriksson, M. Friedrich, and C. Vorschulze, "Variations in the rheology and penetrability of cement-based grouts-an experimental study," Cement and Concrete Research, vol. 34, no. 7, pp. 1111-1119, 2004.

[28] M. Axelsson, G. Gustafson, and Å. Fransson, "Stop mechanism for cementitious grouts at different water-to-cement ratios," Tunnelling and Underground Space Technology, vol. 24, no. 4, pp. 390-397, 2009.

[29] W. Qing, Z. Qing, S. Tang et al., "The rheological test and application research of glass fiber cement slurry based on plugging mechanism of dynamic water grouting," Construction and Building Materials, vol. 189, pp. 119-130, 2018.

[30] O. Turan, N. Chakraborty, and R. J. Poole, "Laminar RayleighBenard convection of yield stress fluids in a square enclosure," Journal of Non-Newtonian Fluid Mechanics, vol. 171-172, pp. 83-96, 2012.

[31] Q. Liu, G. Lei, X. Peng, C. Lu, and L. Wei, "Rheological characteristics of cement grout and its effect on mechanical properties of a rock fracture," Rock Mechanics and Rock Engineering, vol. 51, no. 2, pp. 613-625, 2018. 